+For publication in Energy Conversion and Management

\title{
Integrated process for synthetic natural gas production from coal and coke-oven gas with high energy efficiency and low emission
}

\author{
Yi Man, Siyu Yang, Yu Qian* \\ School of Chemical Engineering, South China University of Technology, Guangzhou, 510640, \\ People's Republic of China
}

*Corresponding author:

Phone: +86-20-87113046

Email: ceyuqian@scut.edu.cn

Website: $\underline{\text { www2.scut.edu.cn/ce/pse/qianyuen.htm }}$ 


\section{Abstract}

There was a rapid development of coal to synthetic natural gas (SNG) projects in

3 the last few years in China. The research from our previous work and some other

4 researchers have found coal based SNG production process has the problems of

5 environmental pollution and emission transfer, including $\mathrm{CO}_{2}$ emission, effluent

6 discharge, and high energy consumption. This paper proposes a novel co-feed process

7 of coal and coke-oven gas to SNG process by using a dry methane reforming unit to

8 reduce $\mathrm{CO}_{2}$ emissions, more hydrogen elements are introduced to improve resource

9 efficiency. It is shown that the energy efficiency of the co-feed process increases by

$4 \%, \mathrm{CO}_{2}$ emission and effluent discharge is reduced by $60 \%$ and $72 \%$, whereas the

11 production cost decreases by $16.7 \%$, in comparison to the conventional coal to SNG

12 process. As coke-oven gas is a waste gas in most of the coking plant, this process also

13 allows to optimize the allocation of resources.

15 Keywords: Coal gasification; Coke-oven gas; $\mathrm{SNG}$; Energy efficiency; $\mathrm{CO}_{2}$ emission 


\section{Introduction}

In China, coal accounts for $67.4 \%$ of the total energy consumption [1]. Too much coal consumption, insufficiently clean processing and burning have brought about serious haze problem in China. Using natural gas to replace coal is one of the key measures to tackle with the air pollution caused by coal combustion [2]. However, the production of natural gas is only $1.57 \times 10^{11} \mathrm{~m}^{3}$ (including the production of shale gas) while the natural gas consumption is about $2.5 \times 10^{11} \mathrm{~m}^{3}$ in 2015 [3]. China is facing the problem of supply shortage of natural gas.

Aiming at the promising market opportunity, Chinese industry made a great efforts to push forward coal to synthetic natural gas (CtSNG) process in recent years. Till now, there have been $8.73 \times 10^{10} \mathrm{~m}^{3} / \mathrm{y}$ production capacity of CtSNG projects in commercial operation in China [4].

A schematic diagram of CtSNG process is shown in Fig. 1. Feedstock raw coal is gasified to crude syngas. The crude syngas is sent into the water gas shift (WGS) unit to adjust the hydrogen-to-carbon $(\mathrm{H} / \mathrm{C})$ ratio. Next the syngas is sent into the acid gas removal (AGR) unit to remove $\mathrm{CO}_{2}$ and sulfide. Finally, the clean syngas is sent into methanation unit for producing SNG [5]. Li et al. [6] made a comparison of techno-economic and environmental performance between coal-based SNG and coal directly burning. The results showed that the coal based SNG using in residential sector could relieve urban haze pollution caused by the direct coal burning. However, coal based SNG has nearly two times higher consumption of raw material and 1.65 times higher $\mathrm{CO}_{2}$ emission than coal burning. 


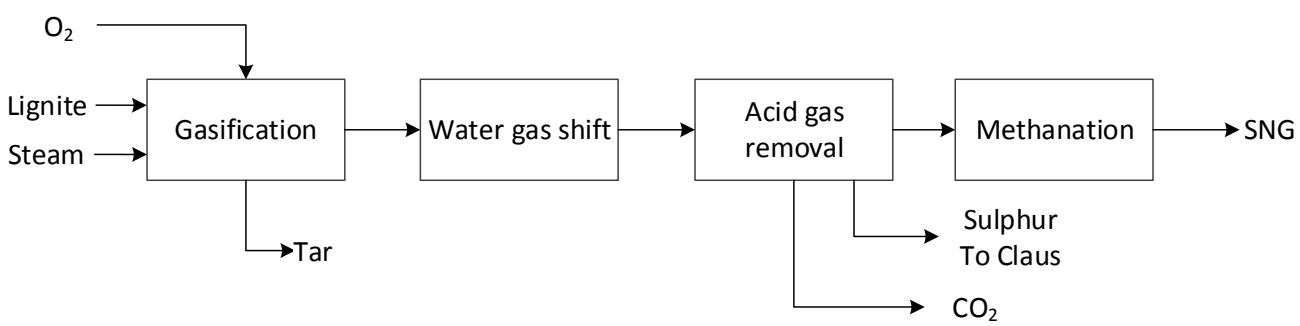

Fig. 1. Schematic diagram of $\mathrm{CtSNG}$

CtSNG process uses lignite as the feedstock due to the limitation of resource allocation. That means the crude syngas from gasification would contain large amount of $\mathrm{CO}_{2} . \mathrm{H} / \mathrm{C}$ ratio of the crude syngas is around $2.3-2.7$, while the required $\mathrm{H} / \mathrm{C}$ ratio for methanation is about 3.1-3.3. The syngas is lack of hydrogen source. $\mathrm{CO}$ of the syngas needs to be converted to $\mathrm{H}_{2}$ in WGS unit. It results in a high emission of $\mathrm{CO}_{2}$ and waste of carbon resource, as well as very high consumption of energy in the WGS unit. Meanwhile, the crude syngas from Lurgi gasification needs to be washed with water to remove the phenol and ammonia. This process generates almost $98 \%$ waste water of the CtSNG process [7]. To treat the effluent with high concentration of phenol and ammonia would consume large amount of energy together with high production cost. Discharge of the effluent without fully treatment would cause serious impact to the environment [8].

Coke-oven gas (COG) is generated in the coking process as a by-product of coal carbonization. The annual COG production is estimated at $7 \times 10^{10} \mathrm{~m}^{3}$ in China [9]. However, most of the COG is directly discharged into the atmosphere. It causes considerable energy waste and serious environmental consequences [10]. COG is a kind of hydrogen-rich gas, which contains $\mathrm{H}_{2}(55-60 \%), \mathrm{CH}_{4}(23-27 \%)$, $\mathrm{CO}(5-8 \%)$, $\mathrm{N}_{2}(3-6 \%), \mathrm{CO}_{2}$ (less than 2\%). Co-feed system could take advantage of coal and 
COG to produce syngas with suitable H/C ratio. Authors' previous work [11] on COG assisted coal to olefins process found that the energy efficiency of co-feed system improved by $10 \%$ and the $\mathrm{CO}_{2}$ emission decreased by $85 \%$ when compared with single coal feed. The co-feed process of coal and COG to SNG is a promising alternatives in dealing with the problems of high $\mathrm{CO}_{2}$ emission and energy consumption. In China, most of CtSNG projects are surrounded by coal coking plants. Plentiful COG source makes assurance for feedstock supply for the co-feed system of coal and COG to SNG process.

Following the above ideas, this paper proposes a novel co-feed process of coal and COG to SNG with high energy efficiency and low $\mathrm{CO}_{2}$ emission. The co-feed process integrates a dry methane reforming unit to reduce $\mathrm{CO}_{2}$ emission, and uses the hydrogen resource in $\mathrm{COG}$ to raise the $\mathrm{H} / \mathrm{C}$ ratio of the syngas. A conceptual design and a techno-economic analysis for the co-feed process is put forward in this paper.

\section{Coal and coke-oven gas to SNG process}

The schematic diagram of the proposed co-feed process of coal and COG to produce SNG (CGtSNG) is shown in Fig. 2. CGtSNG process contains coal gasification unit, acid gas removal unit, and methanation unit. However, it removes the WGS unit, while adds a COG separation unit and a dry methane reforming (DMR) unit compared with CtSNG process. Part of methane from COG is sent into DMR unit to react with $\mathrm{CO}_{2}$ from the coal gasification unit. DMR unit produces clean syngas and reduces $\mathrm{CO}_{2}$ emission. The syngas with suitable $\mathrm{H} / \mathrm{C}$ ratio for methanation is 

from COG.

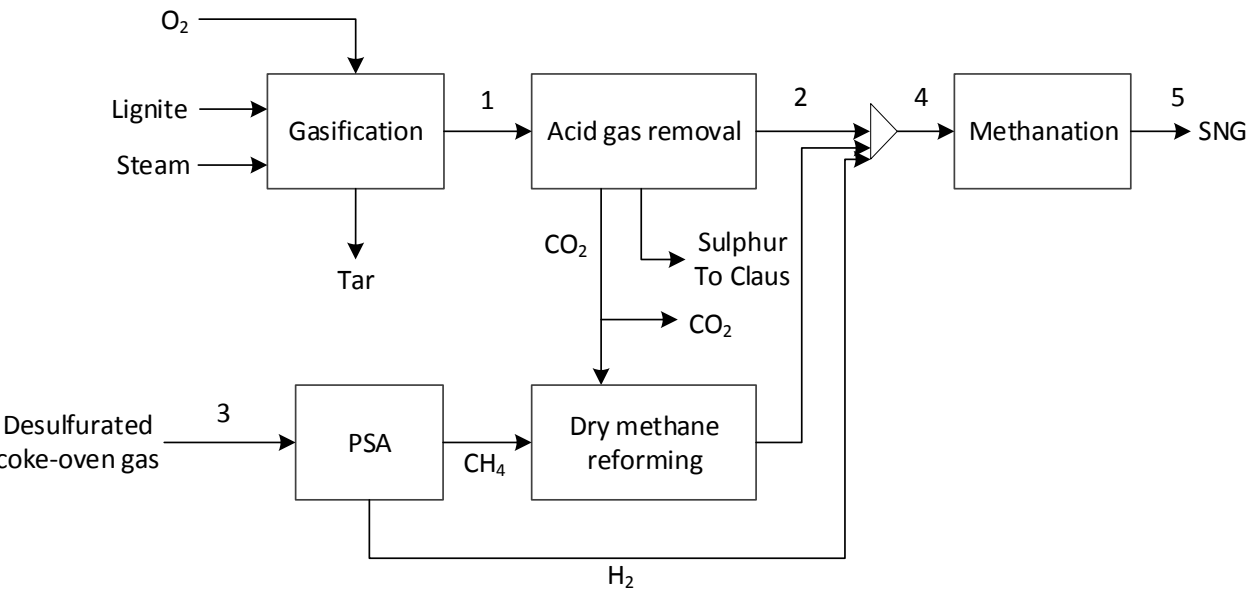

81

obtained by adjusting the proportion of DMR syngas, coal gasification syngas, and $\mathrm{H}_{2}$

Fig. 2. Proposed schematic diagram of CGtSNG process

CGtSNG process is composed of three subsystems: (1) coal gasification and syngas clean; (2) COG separation and dry methane reforming; (3) methanation. The subsystems are introduced as follows. Feedstock composition of CGtSNG is shown in Table 1. The proximate and ultimate analysis of lignite is shown in Table 2 . The data is referred to the lignite from Shengli coalfield of Xilinhot, China. To facilitate comparison between CGtSNG and CtSNG, the production capacity of SNG in CGtSNG is set to 4.0 billion $\mathrm{m}^{3} / \mathrm{y}$, same as industrial CtSNG project of Datang Corporation in Chifeng, China [7].

Table 1 Feedstock for CGtSNG process

\begin{tabular}{cccc}
\hline Raw material & Temperature, ${ }^{\circ} \mathrm{C}$ & Pressure, $\mathrm{MPa}$ & Mass flow, $\mathrm{t} / \mathrm{h}$ \\
\hline Lignite & 25 & 4.0 & 558 \\
COG & 25 & 2.5 & 470 \\
Water & 25 & 0.4 & 1670 \\
Oxygen & 40 & 4.0 & 94.5 \\
\hline
\end{tabular}


Table 2 Proximate and ultimate analysis of lignite

\begin{tabular}{|c|c|c|c|c|c|c|c|c|c|}
\hline & \multicolumn{4}{|c|}{ proximate analysis (wt. \%, ar) } & \multicolumn{5}{|c|}{ ultimate analysis (wt. \%, ar) } \\
\hline & $\mathrm{M}_{\mathrm{t}}$ & $\mathrm{M}_{\mathrm{ad}}$ & $\mathrm{V}_{\text {daf }}$ & A & $\mathrm{C}$ & $\mathrm{H}$ & $\mathrm{O}$ & $\mathrm{N}$ & $\mathrm{S}$ \\
\hline lignite & 36.9 & 17.8 & 42.1 & 9.23 & 40.1 & 2.5 & 9.6 & 0.5 & 1.2 \\
\hline
\end{tabular}

93

\subsection{Coal gasification and syngas clean}

Due to the resource allocation limitation, all the coal to SNG processes in China use lignite as the raw material. That means only Lurgi and BGL gasification technologies could be used in CtSNG. The syngas from Lurgi gasification contains 39\% $\mathrm{H}_{2}, 14 \% \mathrm{CO}$, and $32 \% \mathrm{CO}_{2}$. The syngas from BGL gasification contains $28 \% \mathrm{H}_{2}, 55 \%$ $\mathrm{CO}$, and $6 \% \mathrm{CO}_{2}$. BGL has advantage in low $\mathrm{CO}_{2}$ content. However, $\mathrm{H} / \mathrm{C}$ ratio of BGL gasification syngas is as low as 0.5 , while the $\mathrm{H} / \mathrm{C}$ ratio of Lurgi gasification syngas is 2.7 . For methanation, the $\mathrm{H} / \mathrm{C}$ ratio is required above 3.05 at least. That means a large scale of water gas shift unit is needed to convert $\mathrm{CO}$ into $\mathrm{CO}_{2}$ and $\mathrm{H}_{2}$ to raise the $\mathrm{H} / \mathrm{C}$ ratio. The total amount $\mathrm{CO}_{2}$ for $\mathrm{CtSNG}$ process of $\mathrm{BGL}$ is $18.8 \%$ higher than that of Lurgi. That also means that the handling scale of coal gasification unit and acid gas removal unit should be enlarge which causes the increasing of capital investment and operation cost. In China, the existent CtSNG projects in commercial operation uses Lurgi gasification technology.

The subsystem of coal gasification and syngas clean selects Lurgi pressurized coal gasification technology and Rectisol methanol washing technology as the simulation model referred to the CtSNG project of Datang Corparation in Chifeng, China. The flowsheet of this subsystem is shown in Fig. 3. 


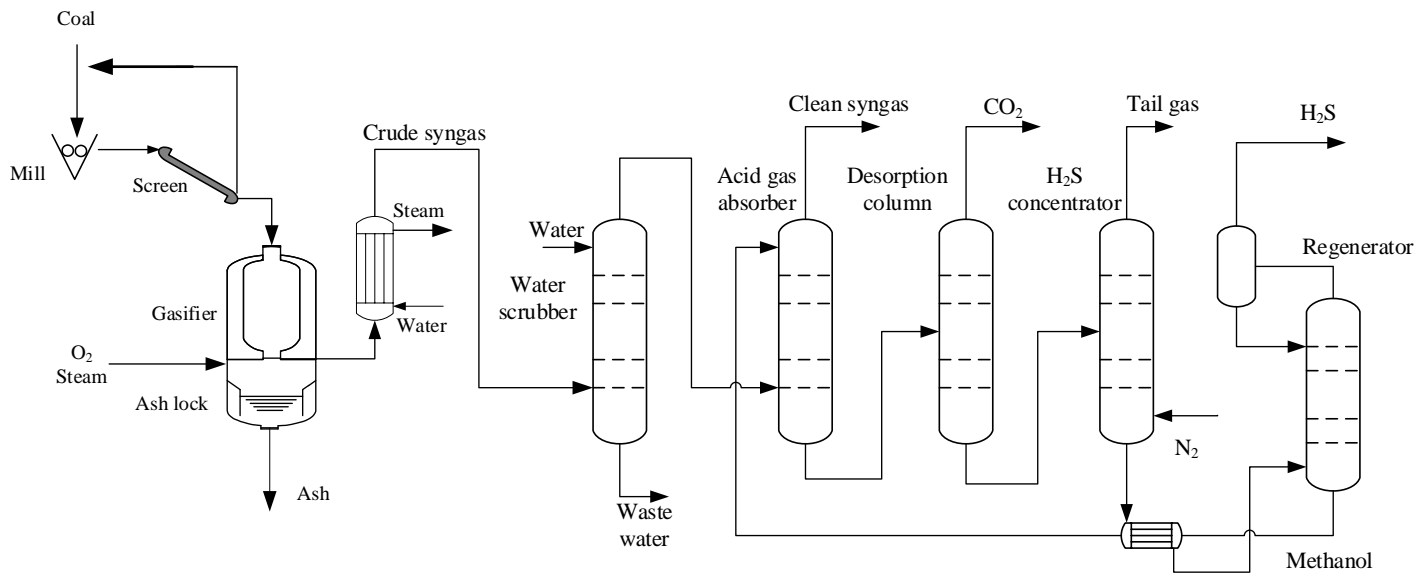
121 equilibrium by the minimum of Gibbs free energy.

122

123

124

125

126

127

128

$$
\mathrm{C}+0.5 \mathrm{O}_{2} \rightarrow \mathrm{CO}
$$

$\mathrm{C}+\mathrm{O}_{2} \rightarrow \mathrm{CO}_{2}$

$$
\mathrm{C}+\mathrm{H}_{2} \mathrm{O} \rightarrow \mathrm{CO}+\mathrm{H}_{2}
$$

$$
\mathrm{C}+\mathrm{CO}_{2} \rightarrow 2 \mathrm{CO}
$$

$$
\mathrm{C}+2 \mathrm{H}_{2} \rightarrow \mathrm{CH}_{4}
$$

$$
\mathrm{C}+\mathrm{H}_{2} \mathrm{O} \rightarrow \mathrm{CO}_{2}+\mathrm{H}_{2}
$$

$$
\mathrm{H}_{2}+0.5 \mathrm{O}_{2} \rightarrow \mathrm{H}_{2} \mathrm{O}
$$

Fig. 3. Subsystem flowsheet of coal gasification and syngas clean

In coal gasification process, lignite is sent into gasifier together with oxygen from air separation unit (ASU) and steam. This process begins with lignite drying and pyrolysis, and continues with combustion and steam gasification. Main reactions in gasification process is shown in Eq. (1) - (9) [12].The product crude syngas of gasification mainly includes $\mathrm{CO}, \mathrm{H}_{2}, \mathrm{CH}_{4}, \mathrm{H}_{2} \mathrm{O}$, and $\mathrm{CO}_{2}$, together with some of sulfide, hydrocarbon, tar, phenol, and ammonia, etc. The gasification process is modeled by RGibbs reactor model and Peng-Robinson state equation is used as the equilibrium properties method [12]. All reactions are simulated based on chemical 
$\mathrm{CO}+0.5 \mathrm{O}_{2} \rightarrow \mathrm{CO}_{2}$

$\mathrm{CH}_{4}+2 \mathrm{O}_{2} \rightarrow \mathrm{CO}_{2}+2 \mathrm{H}_{2} \mathrm{O}$

CtSNG process uses Lurgi type MARK-IV gasifier. The crude syngas contains $39 \% \mathrm{H}_{2}, 14 \% \mathrm{CO}, 32 \% \mathrm{CO}_{2}$ and $15 \% \mathrm{CH}_{4}$. The high content of $\mathrm{CO}_{2}$ is because of the high feedstock of the steam. The impact of steam/coal feedstock ratio on mole fraction of $\mathrm{H}_{2}, \mathrm{CO}, \mathrm{CO}_{2}$, and $\mathrm{CH}_{4}$ of the syngas is plotted in Fig. 4. With the increasing of steam/coal feedstock ratio, the $\mathrm{H}_{2}, \mathrm{CH}_{4}$, and $\mathrm{CO}_{2}$ content of the syngas increases, while $\mathrm{CO}$ decreases. When the feedstock ratio is around 0.9 , the composition of the crude syngas is very close to the industrial data of the CtSNG project of Datang Corporation.

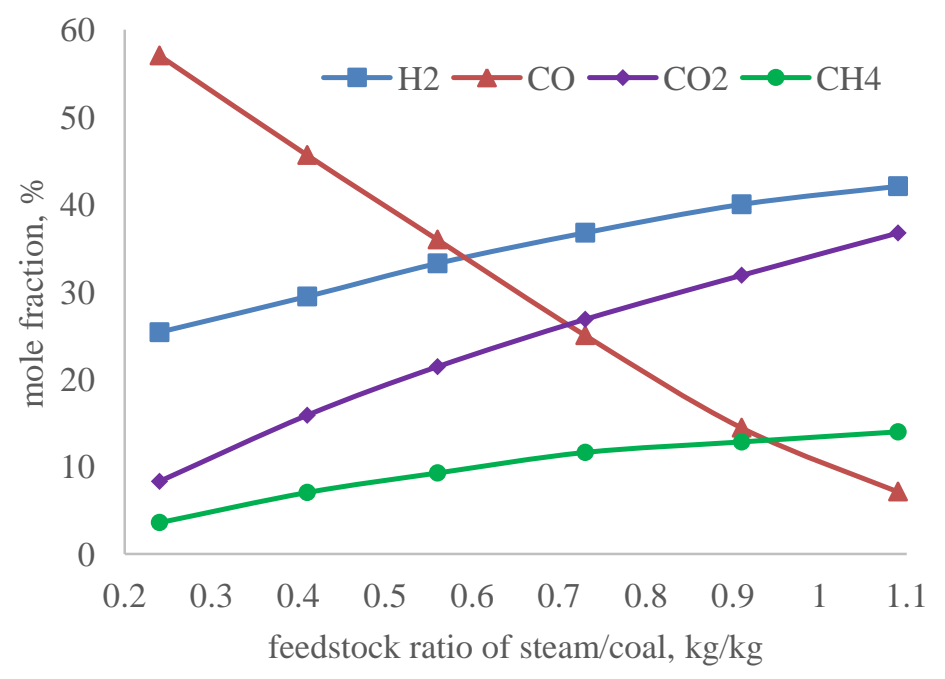

Fig. 4. Mole fraction of the $\mathrm{H}_{2}, \mathrm{CO}, \mathrm{CO}_{2}$, and $\mathrm{CH}_{4}$ with different steam/coal feedstock ratio Crude syngas from the gasifier is sent into an exhaust boiler to generate high temperature steam with $0.5 \mathrm{MPa}$. Next the crude syngas is sent into a water scrubber

143 to remove most of the particulate matter and gaseous impurity which is easily 
dissolved in water, such as phenol and ammonia. Then the produced syngas is sent into AGR unit for further cleaning.

As shown in the right part of Fig. 3, AGR unit contains an absorber (uses chilled methanol to absorb $\mathrm{H}_{2} \mathrm{~S}$, $\mathrm{COS}$ and $\mathrm{CO}_{2}$ ), a $\mathrm{CO}_{2}$ desorption column (desorbs $\mathrm{CO}_{2}$ from the $\mathrm{CO}_{2}$-rich methanol), an $\mathrm{H}_{2} \mathrm{~S}$ concentrator (collects and concentrates $\mathrm{H}_{2} \mathrm{~S}$ from the $\mathrm{H}_{2} \mathrm{~S}$-rich methanol) and a methanol regenerator. Modelling and simulation of the water scrubber and AGR unit has been presented in the previous works on improved Rectisol methanol washing technology from parts of the authors [13]. Table 3 lists the energy consumption of AGR unit in CGtSNG.

Table 3 Energy consumption of AGR unit

\begin{tabular}{cccc}
\hline Items & Specification & Metric & Consumption \\
\hline Circulating cooling water & $25^{\circ} \mathrm{C}$ & $\mathrm{t} / \mathrm{h}$ & 3170 \\
Electricity & $\backslash$ & $\mathrm{kW}$ & 5400 \\
LP steam & $0.5 \mathrm{MPa}$ & $\mathrm{t} / \mathrm{h}$ & 41 \\
MP steam & $2.5 \mathrm{MPa}$ & $\mathrm{t} / \mathrm{h}$ & 20 \\
LP nitrogen & $0.5 \mathrm{MPa}$ & $\mathrm{m}^{3} / \mathrm{h}$ & 3240 \\
Cryogenic energy & $-40{ }^{\circ} \mathrm{C}$ & $\mathrm{kW}$ & 28800 \\
\hline
\end{tabular}

\subsection{COG separation and dry methane reforming}

In most of the coal based chemical process, especially the process using Texaco or Shell gasification technologies, the source of $\mathrm{CO}_{2}$ emission mainly comes from the WGS unit. The existent coal based co-feed processes usually achieve the goal of $\mathrm{CO}_{2}$ reduction by reducing the shift degree of WGS unit. However, due to the resource allocation limitation, the present CtSNG processes in China adopt lignite as the feedstock and use Lurgi or similar gasification technology. The advantage of Lurgi gasification is that the $\mathrm{H} / \mathrm{C}$ ratio of the gasification syngas is as high as $2.1-2.4$. That 
163

164 177 into DMR unit and $\mathrm{H}_{2}$ will be mixed with the syngas for adjusting the $\mathrm{H} / \mathrm{C}$ ratio in the 178 later step. The subsystem flowsheet of COG separation and dry methane reforming is 179 shown in Fig. 5.

means the shift degree could be so low that the energy consumption could be decreased in the WGS unit. The disadvantage of Lurgi gasification is the high $\mathrm{CO}_{2}$ generation. Syngas from Lurgi gasification contains $35 \% \mathrm{CO}_{2}$, which accounts for more than $80 \%$ of the $\mathrm{CO}_{2}$ emission in $\mathrm{CtSNG}$. In co-feed process for producing $\mathrm{SNG}$, only use hydrogen-rich resource to reduce the shift degree is not an effective solution for reducing $\mathrm{CO}_{2}$ emission and energy consumption. The proposed co-feed process in this paper adds a DMR unit to recycle the $\mathrm{CO}_{2}$ from Lurgi gasification unit.

DMR offers valuable environmental benefits. It is an effective way to recycle $\mathrm{CO}_{2}$ from the coal gasification process [14]. In DMR reaction, excessive $\mathrm{H}_{2}$ would inhibit reaction equilibrium of DMR. And there may occur the side reaction, a reverse WGS reaction. This reaction would take away the useful $\mathrm{H}_{2}$ in the syngas, and it is a strongly endothermic process and consumes considerable amount of energy [14]. COG has to be separated into $\mathrm{H}_{2}$ and $\mathrm{CH}_{4}$ before DMR. A pressure swing adsorption (PSA) unit is used for COG separation. The separated $\mathrm{CH}_{4}$ from $\mathrm{COG}$ will be sent 


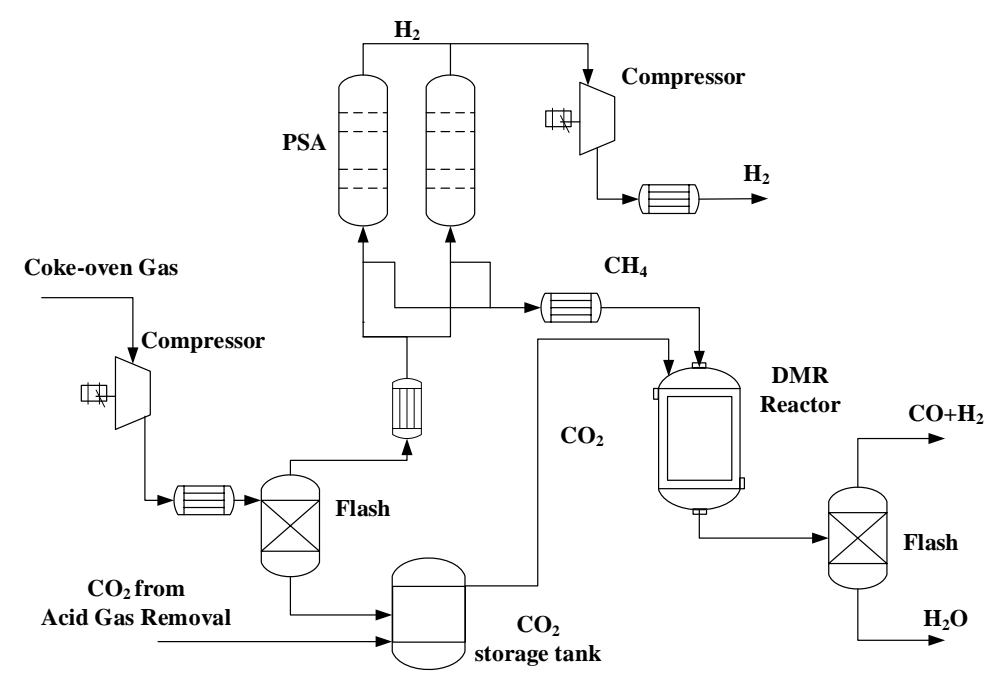
is used in DMR unit with the reaction temperature of $700{ }^{\circ} \mathrm{C}$. In such condition, the 183 conversion rate of $\mathrm{CH}_{4}$ and $\mathrm{CO}_{2}$ could be achieved up to 95\% [15]. Peng-Robinson state equation is used as the equilibrium properties method in Aspen Plus. And RGibbs reactor model is used in simulations [16].

$\mathrm{CO}_{2}+\mathrm{CH}_{4} \rightarrow 2 \mathrm{CO}+2 \mathrm{H}_{2} ; \Delta \mathrm{H}=+247 \mathrm{~kJ} \cdot \mathrm{mol}^{-1}$

$\mathrm{CO}_{2}+\mathrm{H}_{2} \rightarrow \mathrm{CO}+\mathrm{H}_{2} \mathrm{O} ; \Delta \mathrm{H}=+41.2 \mathrm{~kJ} \bullet \mathrm{mol}^{-1}$

RGibbs reactor model predicts a thermodynamically limited maximum methane conversion of $95 \%$ at $700{ }^{\circ} \mathrm{C}$ and $0.4 \mathrm{MPa}$. Referred to the work of Luyben [15], the expressions used for the forward and reverse reaction rates of Eq. (10) are given in the 191 following equations.

$$
r_{\mathrm{R}}=1.094 \times 10^{-22} e^{-195900 / R T} P_{\mathrm{CO}} P_{\mathrm{H}_{2}}
$$

For the reverse water gas shift reaction of Eq. (11), a simple kinetic expression is assumed with the following equation referred to the work of Luyben [15]. 


$$
r_{\mathrm{RWGS}}=10^{-11} e^{-50000 / R T} P_{\mathrm{CO}_{2}} P_{\mathrm{H}_{2}}
$$

By mass balance calculation, the quantity of $\mathrm{CH}_{4}$ sent into DMR accounts for $1.5 \%$ of the SNG production while it reduced $60 \% \mathrm{CO}_{2}$ emission.

Syngas for methanation is obtained from the mixture of coal gasification syngas, DMR syngas, and $\mathrm{H}_{2}$ from COG.

\subsection{Methanation}

Main reaction in methanation is shown in Eq. (15). Eq. (16) only occurs when CO concentration is very low [17]. Referred to the CtSNG project of Datang Corporation, subsystem of methanation selects Davy methanation technology as the simulation model. The flowsheet of this subsystem is shown in Fig. 6. Four sequential adiabatic reactors are used to convert syngas into SNG. The first two reactors are bulk methanation reactors, in which most of the $\mathrm{CO}, \mathrm{CO}_{2}$, and $\mathrm{H}_{2}$ will convert into $\mathrm{CH}_{4}$. The last two reactors are trim methanation reactors. Unreacted gas from bulk methanation reactors is sent into trim methanation reactors for converting the rest of the $\mathrm{CO}, \mathrm{CO}_{2}$, and $\mathrm{H}_{2}$. Methanation reactions are strongly exothermic. The heat released from methanation is recovered by the waste-heat boiler for generating high temperature and pressure stream. Peng-Robinson state equation is used as the equilibrium properties method in Aspen Plus and RPlug reactor model is used in simulations [17].

$\mathrm{CO}+3 \mathrm{H}_{2} \rightarrow \mathrm{CH}_{4}+\mathrm{H}_{2} \mathrm{O} ; \Delta \mathrm{H}=-206 \mathrm{~kJ} / \mathrm{mol}$

$\mathrm{CO}_{2}+4 \mathrm{H}_{2} \rightarrow \mathrm{CH}_{4}+2 \mathrm{H}_{2} \mathrm{O} ; \Delta \mathrm{H}=-165 \mathrm{~kJ} / \mathrm{mol}$ 
of $\mathrm{CO}$ [Eq. (15)] as part of a laboratory data program. The correlation is as follows:

$220 \quad r=\frac{A}{C^{2}} \frac{P_{\mathrm{CO}}}{P_{\mathrm{H}_{2}}^{0.5}}$

221 where $r$ is the reaction rate in $\mathrm{mol} \cdot(\mathrm{g} \cdot \mathrm{s})^{-1}, P$ refers to partial pressure in $\mathrm{kPa}$, and $A$ and

$222 C$ are empirical constants determined at each temperature.

223

The data reported by Yadav and Rinker [18] at 503, 513 and $529 \mathrm{~K}$ were fitted to

a simple Arrhenius equation as follows:

$225 r=0.314 e^{1300\left(\frac{1}{T}-\frac{1}{513}\right)} \frac{P_{\mathrm{CO}}}{P_{\mathrm{H}_{2}}^{0.5}}$

Proper modeling of the methanation should include the effect of the backward

reaction as equilibrium is approached. The complete version of Eq. (15) is as follows:

$r=A_{\mathrm{C}} 0.314 e^{1300\left(\frac{1}{T}-\frac{1}{513}\right)} \frac{P}{P_{\mathrm{H}_{2}}^{0.5}}\left(y_{\mathrm{CO}}-\frac{y_{\mathrm{CH}_{4}} y_{\mathrm{H}_{2} \mathrm{O}}}{y_{\mathrm{H}_{2}}^{3} P^{2} K_{\mathrm{CO}}}\right)$

$229 \quad K_{\mathrm{CO}}=e^{(-38.4523+26270 / T)}$

where $P$ is the pressure in $\mathrm{kPa}, y$ is the component mole fraction, $K_{\mathrm{CO}}$ is the equilibrium constant for Eq. (15) and $A_{\mathrm{C}}$ is the catalyst activity factor. 


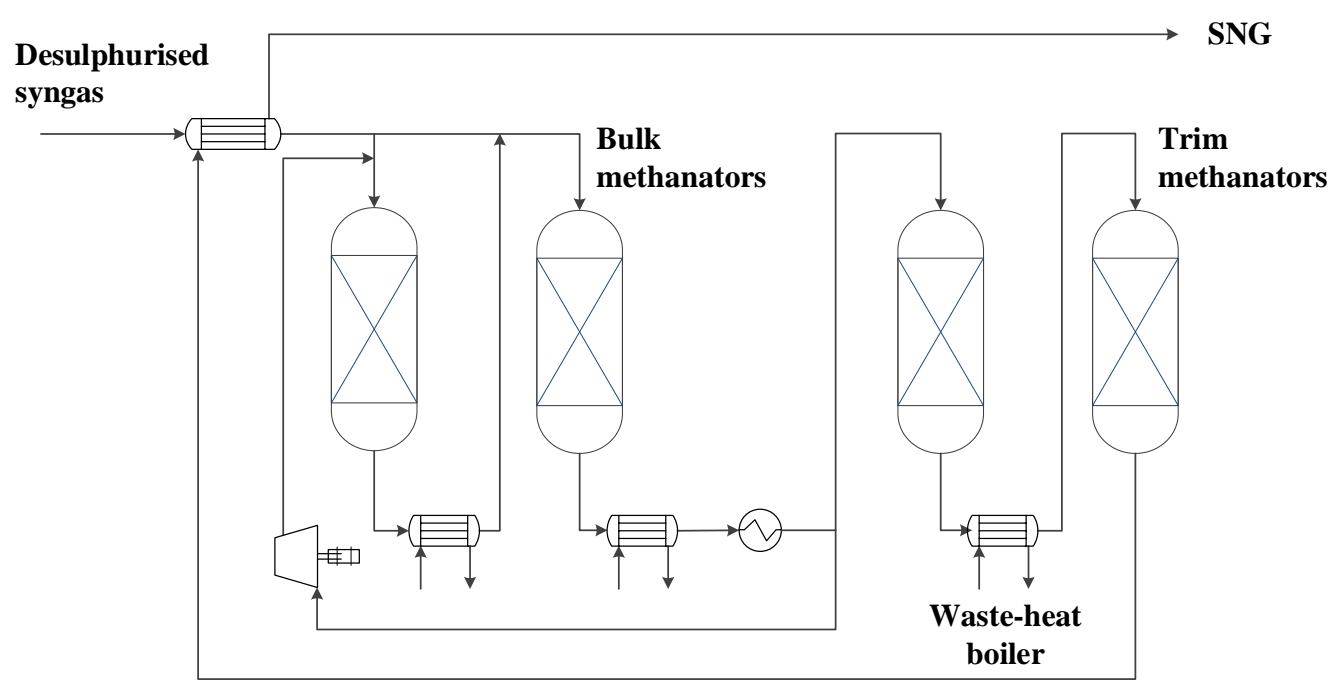

Fig. 6. Subsystem flowsheet of methanation

\subsection{Process simulation of CGtSNG}

The main operation conditions and specifications are shown in Table 4. By

242 simulation, data for each main stream is obtained and shown in Table 5, which

243 includes compositions, temperatures, and pressures. The stream number in Table 5 is

244 referred to Fig. 1. Fig. 7 shows the steam balance of CGtSNG based on the simulation

245 data of Aspen Plus.

Table 4 Main operation conditions of CGtSNG process

\begin{tabular}{ccc}
\hline Unit & Operation conditions & Value \\
\hline Coal gasifier (Lurgi) & Gasification pressure, MPa & 4 \\
& Gasification temperature, ${ }^{\circ} \mathrm{C}$ & $>800$ \\
& Carbon conversion, \% & 99.9 \\
DMR reactor & Reaction pressure, MPa & 0.4 \\
& Reaction temperature, $\mathrm{K}$ & $\sim 700$ \\
Pressure swing adsorption & Carbon conversion, \% & 95 \\
& Hydrogen yield $(\%)$ & $>90$ \\
Acid gas removal & Number of absorber & 2 \\
& Solvent & Rectisol \\
& Overall $\mathrm{H}_{2}$ S removal yield $(\%)$ & 99.5 \\
Methanation & Residual content of CO and $\mathrm{CO}_{2}$ & $<10 \mathrm{ppm}^{\circ}$ \\
\hline
\end{tabular}


Table 5 Simulation results of CGtSNG process

\begin{tabular}{cccccc}
\hline Steam No. & 1 & 2 & 3 & 4 & 5 \\
\hline Mole fraction, $\%$ & & & & & \\
$\mathrm{CO}$ & 14.5 & 21.2 & 5.8 & 17.9 & Trace \\
$\mathrm{CO}_{2}$ & 31.9 & 1.8 & 2.8 & 1.5 & 0.7 \\
$\mathrm{H}_{2}$ & 39.00 & 57.2 & 59.5 & 60.8 & 1.7 \\
$\mathrm{O}_{2}$ & 0.3 & 0.4 & 1.6 & 0.4 & 0 \\
$\mathrm{CH}_{4}$ & 12.8 & 18.8 & 24.4 & 18.9 & 96.8 \\
$\mathrm{C}_{2}+$ & 0.6 & 0.2 & 1.4 & 0.2 & 0 \\
$\mathrm{H}_{2} \mathrm{~S}$ & 0.7 & 0 & 0 & 0 & 0 \\
$\mathrm{~N}_{2}$ & 0.2 & 0.4 & 4.5 & 0.3 & 0.8 \\
Mole flow, kmol/h & 26982.9 & 18707.2 & 45200.9 & 66732.1 & 22321.4 \\
Temperature, ${ }^{\circ} \mathrm{C}$ & 180 & 40 & 25 & 40 & 40 \\
Pressure, MPa & 4 & 4 & 0.1 & 3.3 & 3.3 \\
\hline
\end{tabular}

249

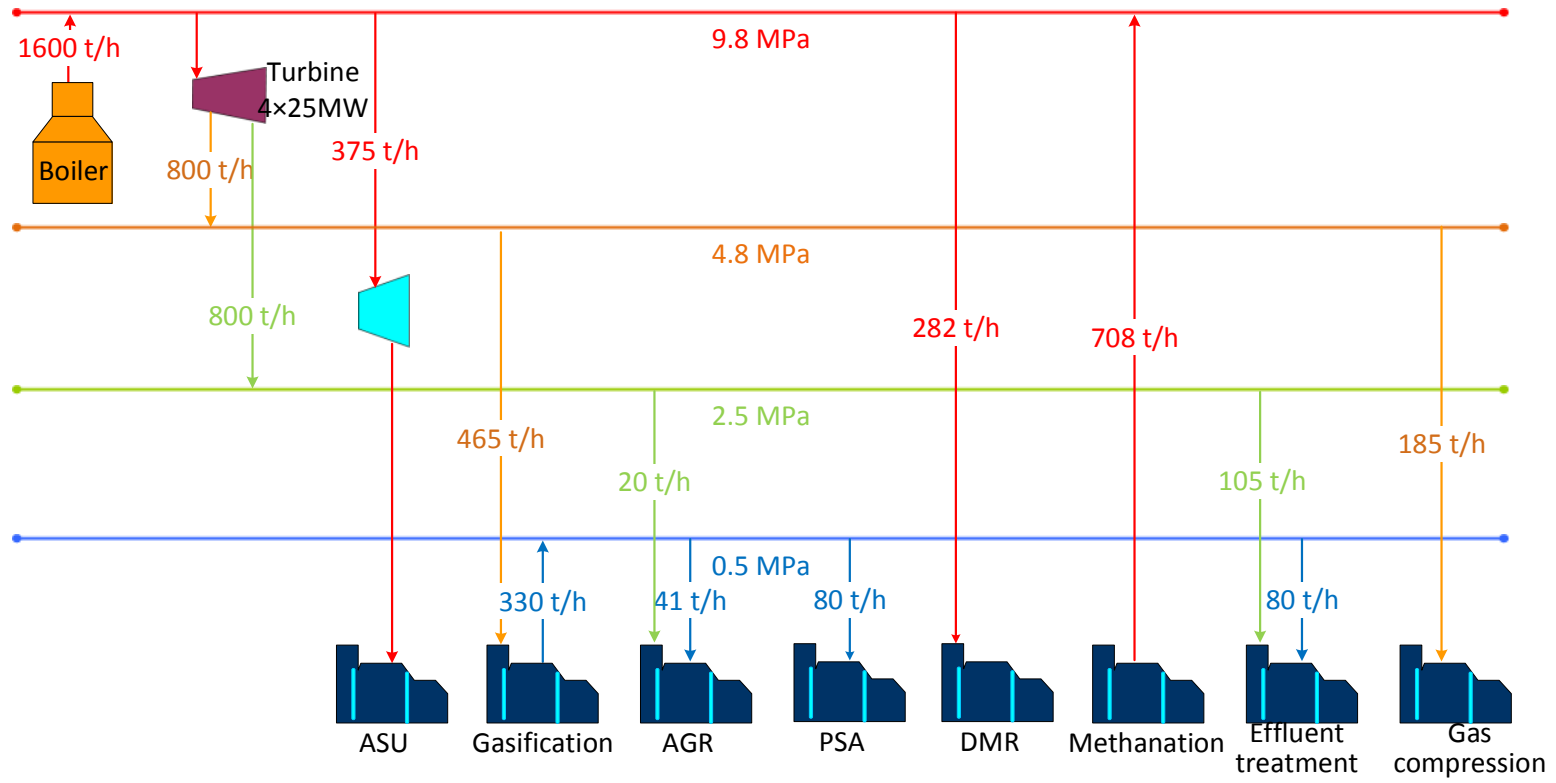

Fig. 7. Steam balance of CGtSNG

\subsection{Key operational variables analysis}

254 gasification syngas, DMR syngas, and $\mathrm{H}_{2}$ from COG. Insufficient COG feedstock rate

255 would result in low H/C ratio of syngas, thereby reduce the yield of SNG production.

256 And insufficient $\mathrm{CH}_{4}$ from $\mathrm{COG}$ could not react with whole content of $\mathrm{CO}_{2}$. As a 
$273 f=\frac{F_{\mathrm{SNG}}^{\text {out }}}{F_{\mathrm{Coal}}^{\text {in }}+F_{\mathrm{COG}}^{\text {in }}} \times 100 \%$ rate of SNG product.

result, the reduction of carbon emission would be little. On the other hand, excessive COG feedstock rate would bring about high $\mathrm{H} / \mathrm{C}$ ratio of syngas. Redundant $\mathrm{H}_{2}$ not only waste the hydrogen resource, but also bring problems in SNG refinement. Suitable range of feedstock rate for COG needs to be found.

$\mathrm{H} / \mathrm{C}$ ratio of the syngas is a very important indicator for methanation reaction. The optimal $\mathrm{H} / \mathrm{C}$ ratio for methanation is in the range 3.05 to 3.2 . The change of $\mathrm{H} / \mathrm{C}$ ratio with different feedstock ratio of COG to coal is analyzed in this paper.

Consumed feedstock of coal affects resource utilization, energy efficiency, and economic benefit. It is also embodies the contribution of the system to $\mathrm{CO}_{2}$ emission. Efficiency of carbon use (treated as an element) is taken as an investigation object when analyzing the technical performance of the process. Elementary carbon efficiency is defined as the ratio of effective carbon compounds of the outlets to effective carbon compounds of the inlets streams [19]. For CGtSNG process, coal (carbon content of lignite is valued as $75 \%$ wt.) and $\mathrm{CH}_{4}$ in $\mathrm{COG}$ are inlet effective compounds, SNG is outlet effective compound. Elementary carbon efficiency of CGtSNG is defined as following equations (23).

where $f$ is the elementary carbon efficiency, $F_{\text {Coal }}^{\text {in }}$ is the mole flow rate of carbon content in coal, $F_{\mathrm{COG}}^{\text {in }}$ is mole flow rate of $\mathrm{CH}_{4}$ in $\mathrm{COG}$, and $F_{\mathrm{SNG}}^{\text {out }}$ is mole flow

The impact of COG/coal feedstock ratio on $\mathrm{H} / \mathrm{C}$ ratio is plotted in Fig. 8. With increase in the feedstock ratio, the $\mathrm{H} / \mathrm{C}$ ratio rises due to the $\mathrm{CO}$ content of 
methanation syngas gradually decrease. When the ratio of COG/coal feedstock reaches $0.8-1.0$, and $\mathrm{H} / \mathrm{C}$ ratio is in the range 3.05-3.2.

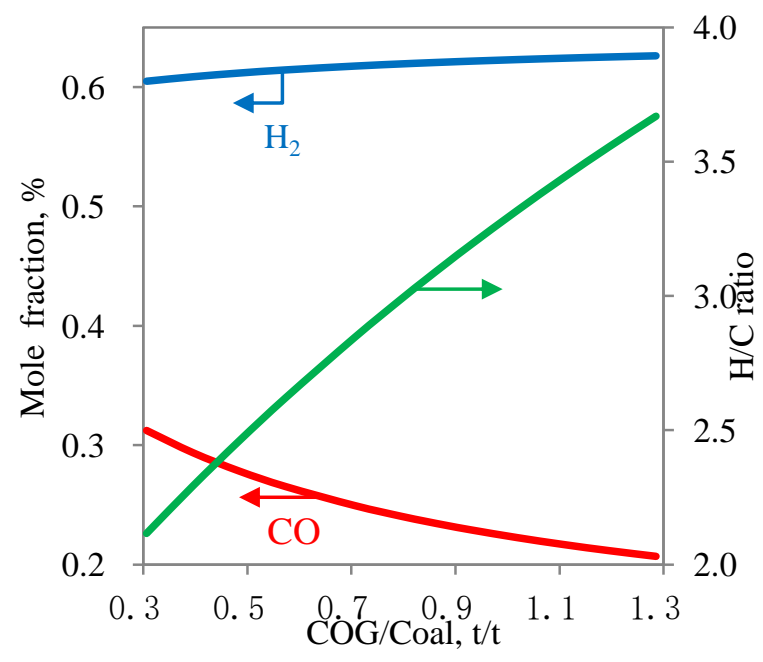

Fig. 8. Impact of $\mathrm{COG} / \mathrm{coal}$ feedstock ratio on $\mathrm{H} / \mathrm{C}$ ratio

The impact of COG/coal feedstock ratio on elementary carbon efficiency and $\mathrm{CO}_{2}$ emission is plotted in Fig. 9. The efficiency of elementary carbon increases with the increase in the feedstock ratio. When the ratio of COG/coal feedstock reaches around 0.9 , almost all $\mathrm{CO}_{2}$ from AGR unit is reacted, the increasing of elementary carbon efficiency becomes smooth. Continuing raise the feedstock would lead to the waste of the raw material and makes a decrease in elementary carbon efficiency.

In consequence, COG/coal feedstock ratio for CGtSNG process should be around $0.8-0.9$. In such conditions, the elementary carbon efficiency reaches up to $70 \%$ and the value of $\mathrm{H} / \mathrm{C}$ ratio is adequate for the methanation process. 


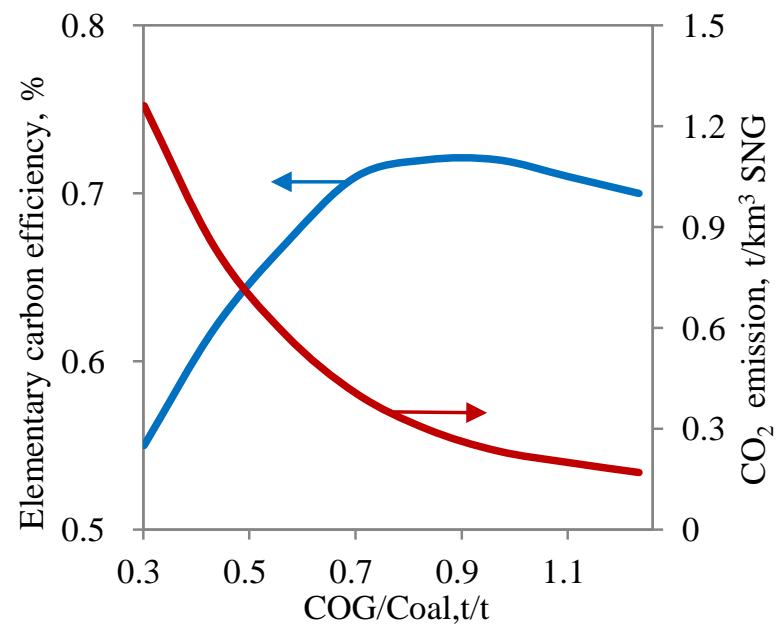

Fig. 9. Impact of COG/coal feedstock ratio on elementary carbon efficiency and $\mathrm{CO}_{2}$ emission

293

3. Coal and coke-oven gas to SNG process without DMR

A co-feed process of coal and COG to produce SNG without DMR unit

(CGtSNG w/o DMR) is designed in this paper, shown in Fig. 10. In this process, mixture, the syngas with suitable $\mathrm{H} / \mathrm{C}$ ratio is sent into methanation unit. Compared 299 with CGtSNG, the PSA and DMR units are cancelled in this process. It avoids the 300 energy consumption of matter conversion. However, $\mathrm{CO}_{2}$ in this process cannot be recycled without DMR reaction. 


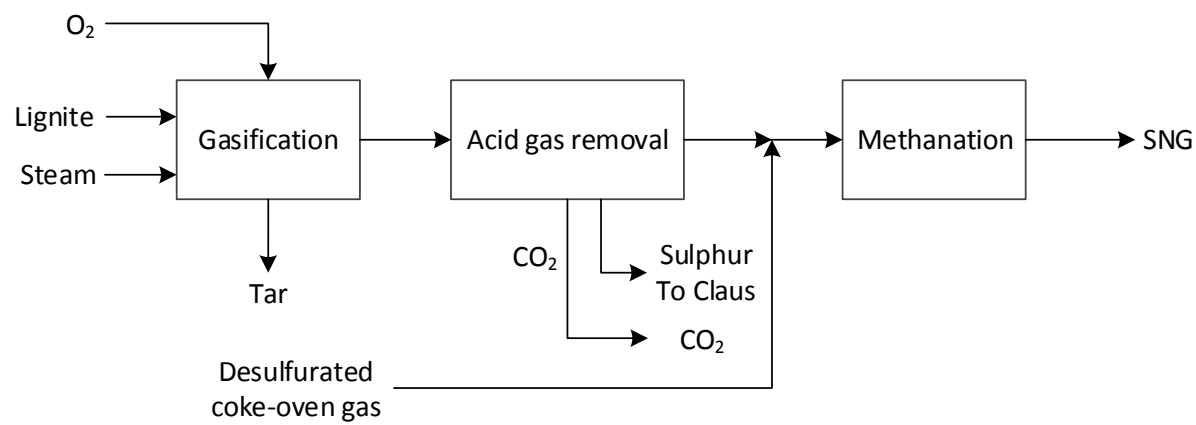

Fig. 10. Schematic diagram of CGtSNG w/o DMR process

\section{Techno-economic analysis of CGtSNG process}

305

\subsection{Energy efficiency}

Table 6 shows the consumption, product output, and energy efficiency of CtSNG, CGtSNG, and CGtSNG w/o DMR processes. Utilities consumption is calculated by the lignite coal consumption for fuel, including steam and power generation. High elementary carbon efficiency makes CGtSNG process need much smaller amount of coal, as raw material, to produce the same amount of SNG. That means the scale of coal gasification, AGR, and ASU units of CGtSNG are also smaller than CGtSNG. The total energy input of CGtSNG is significantly reduced. As a result, energy efficiency of CGtSNG is $4.1 \%$ higher than CtSNG process. CGtSNG w/o DMR process do not make use of $\mathrm{CO}_{2}$. However, WGS unit is canceled in CGtSNG w/o DMR process and the waste of elementary carbon convention is avoided. The energy efficiency of CGtSNG w/o DMR is $7.6 \%$ higher than CtSNG process.

Table 6 Consumption, product output, and energy efficiency

\begin{tabular}{ccccc}
\hline Item & CtSNG [7] & CGtSNG & CGtSNG & Lower heating \\
& & & w/o DMR & value \\
\hline
\end{tabular}




\begin{tabular}{lrrrr} 
Consumption & & & & \\
Lignite, $\mathrm{t}$ & $1.55 \mathrm{E} 7$ & $4.47 \mathrm{E} 6$ & $1.07 \mathrm{E} 7$ & $14.4 \mathrm{MJ} / \mathrm{kg}$ \\
Coke-oven gas, $\mathrm{m}^{3}$ & - & $8.1 \mathrm{E} 9$ & $2.73 \mathrm{E} 9$ & $17.4 \mathrm{MJ} / \mathrm{m}^{3}$ \\
$\quad$ Lignite for fuel & $3.75 \mathrm{E} 6$ & $3.61 \mathrm{E} 6$ & $2.78 \mathrm{E} 6$ & $14.4 \mathrm{MJ} / \mathrm{kg}$ \\
$\quad$ Water, $\mathrm{t}$ & $1.83 \mathrm{E} 7$ & $6.42 \mathrm{E} 6$ & $1.03 \mathrm{E} 7$ & - \\
$\quad$ Total energy input, GJ & $2.77 \mathrm{E} 8$ & $2.57 \mathrm{E} 8$ & $2.42 \mathrm{E} 8$ & - \\
Products output & & & & \\
$\quad \mathrm{SNG}, \mathrm{m}^{3}$ & $4.0 \mathrm{E} 9$ & $4.0 \mathrm{E} 9$ & $4.0 \mathrm{E} 9$ & $35.99 \mathrm{MJ} / \mathrm{m}^{3}$ \\
$\mathrm{CO}_{2}$ emission, $\mathrm{t}$ & $7.85 \mathrm{E} 6$ & $3.14 \mathrm{E} 6$ & $5.67 \mathrm{E} 6$ & - \\
$\quad$ Total energy of SNG, GJ & $1.44 \mathrm{E} 8$ & $1.44 \mathrm{E} 8$ & $1.44 \mathrm{E} 8$ & \\
Energy efficiency, \% & 51.9 & 56.0 & 59.5 & - \\
\hline
\end{tabular}

\section{2. $\mathrm{CO}_{2}$ emission and effluent discharge}

DMR with 4.0 billion $\mathrm{m}^{3} / \mathrm{y}$ SNG production capacity is shown is Fig. 11. The total $\mathrm{CO}_{2}$ emission of CtSNG $7.85 \times 10^{6} \mathrm{t} / \mathrm{y}$, and the mass flow of waste water is $1670 \mathrm{~m}^{3} / \mathrm{h}$. total effluent discharge [7]. Hence, the calculation of effluent in this paper only considers the waste water from coal gasification unit. The waste water is generated by crude coal gas washing. The amount of waste water is depended on the amount of crude coal gas. The total amount of waste water of CGtSNG and CGtSNG w/o DMR could be obtained by calculating the amount of the crude coal gas.

The increase in elementary carbon efficiency of CGtSNG makes the process emit less $\mathrm{CO}_{2}$ and the application of DMR unit takes use of the $\mathrm{CO}_{2}$ from coal gasification. As a result, $\mathrm{CO}_{2}$ emission of CGtSNG decreases by $60 \%$ in comparison of CtSNG. The consumption for lignite in CGtSNG process is around $29 \%$ of that in CtSNG process. That means the amount of crude syngas from coal gasification of CGtSNG is much smaller than CtSNG. Water usage for crude syngas scrubbing would have a 
335

corresponding decrease. The result shows the effluent discharge of CGtSNG is reduced by $72 \%$. This will reduce the water consumption for the production process and relieve the pressure on effluent treatment.

For CGtSNG w/o DMR process, $\mathrm{CO}_{2}$ is not reused. However, the canceled WGS unit makes this process generate less $\mathrm{CO}_{2}$. And the introduction of $\mathrm{COG}$ as the raw material also saves some coal consumption. As a result, $\mathrm{CO}_{2}$ emission of this process decreases by $27.8 \%$ and the effluent discharge decreases by $30.9 \%$.

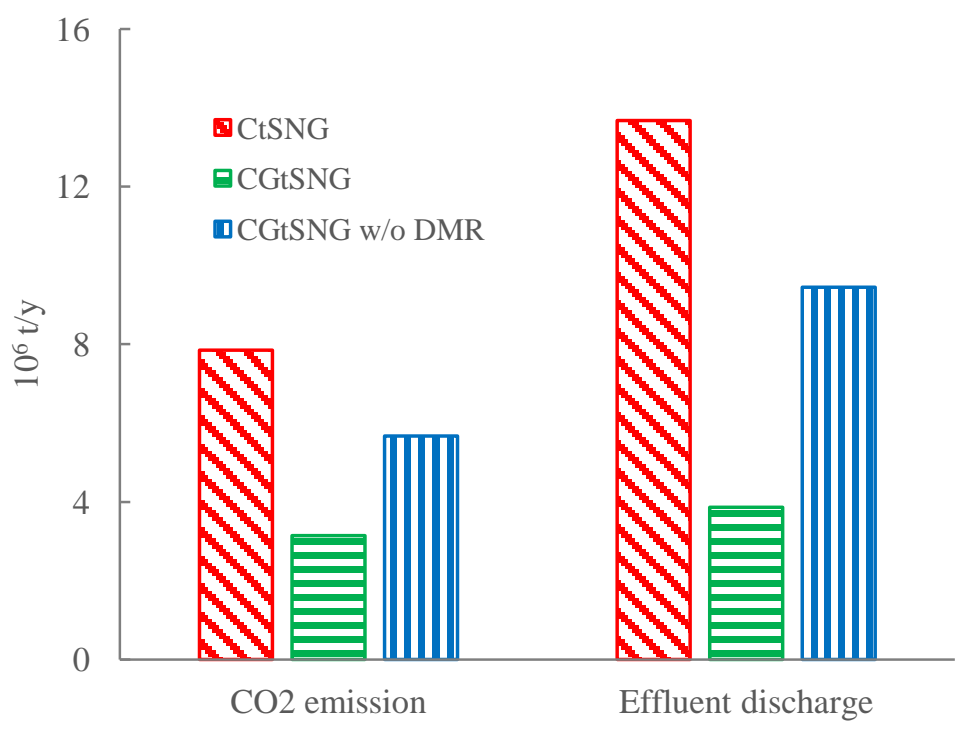

Fig. 11. $\mathrm{CO}_{2}$ emission and effluent discharge

\subsection{Economic performance}

Economic performance for CGtSNG process with the production capacity of 4.0 billion $\mathrm{m}^{3} / \mathrm{y}$ SNG is analyzed and made a comparison to the CtSNG of Datang Corporation. 
previous works [20].

356

where $I_{1}$ and $Q_{1}$ are the fixed capital investment and the production capacity of the current project; $I_{2}$ and $Q_{2}$ are the fixed capital investment and the production capacity of the planned project; $\theta$ is the domestic-made factor; $\mathrm{n}$ is scale exponent, $\mathrm{n}=0.6$ is a common value for chemical processes.

Table 7 Summary of investment data for main equipment components

\begin{tabular}{llccc}
\hline \multicolumn{1}{c}{ Unit } & \multicolumn{1}{c}{ Benchmark } & $Q_{1}$ & $\theta$ & $I_{1}\left(10^{8} \mathrm{CNY}\right)$ \\
\hline Air separation [11] & Oxygen supply & $21.3 \mathrm{~kg} / \mathrm{s}$ & 0.50 & 2.83 \\
Coal gasification [21] & Daily coal input & $39.2 \mathrm{~kg} / \mathrm{s}$ & 0.80 & 4.84 \\
Pressure swing adsorption [11] & Hydrogen supply & $21.3 \mathrm{~kg} / \mathrm{s}$ & 0.50 & 2.83 \\
Dry methane reforming [11] & Material caloric value & $716 \mathrm{MW}$ & 0.65 & 3.84 \\
Water gas shift [22] & Coal caloric value & $1377 \mathrm{MW}$ & 0.67 & 2.47 \\
Acid gas removal [22] & $\mathrm{CO}_{2}$ absorption & $2064.4 \mathrm{~mol} / \mathrm{s}$ & 0.65 & 2.03 \\
Methanation [23] & Syngas input & $10810 \mathrm{~mol} / \mathrm{s}$ & 0.65 & 1.26 \\
\hline
\end{tabular}

The components of the total capital investment could be determined according to their ratios to the equipment investment. The ratios are shown in Table 8 and the calculation follows Eq. (25)

$\mathrm{TCI}=I \cdot\left(1+\sum_{i} R F_{i}\right)$

where TCI the total capital investment, $I$ is the fixed capital investment, and $R F_{i}$ is the ratio factor of capital investment of component $i$. 


\begin{tabular}{lc}
\hline Component & Ratio factor (RF, \%) [24] \\
\hline (1) Direct investment & 100 \\
(1.1) Equipment & 48 \\
(1.2) Installation & 24 \\
(1.3) Instruments and controls & 57 \\
(1.4) Piping & 29 \\
(1.5) Electrical & 71 \\
(1.6) Buildings(including services) & 5 \\
(1.7) Land & \\
(2) Indirect investment & 48 \\
(2.1) Engineering and supervision & 43 \\
(2.2) Construction expenses & 19 \\
(2.3) Contractor's fee & 33 \\
(2.4) Contingency & 477 \\
(3) Fixed capital investment & 80 \\
(4) Working capital & 557 \\
(5) Total capital investment & \\
\hline
\end{tabular}

372 capacity could be estimated to be around $1.926 \times 10^{10} \mathrm{CNY}$ and $17.99 \times 10^{10} \mathrm{CNY}$.

373 CGtSNG adds a COG separation and DMR units. However, it removes the 374 high-energy-consumption WGS unit. Correspondingly, the scale of acid gas removal 375 unit becomes smaller. At the same time, number of the gasifiers reduces to a quarter 376 of the CtSNG process because of the improvement of the coal utilization efficiency.

377 CGtSNG w/o DMR process canceled the WGS unit in CtSNG and PSA and DMR units in CGtSNG. As a result, the total capital investment for CGtSNG and CGtSNG w/o DMR processes are reduced by $4 \%$ and $10 \%$. 


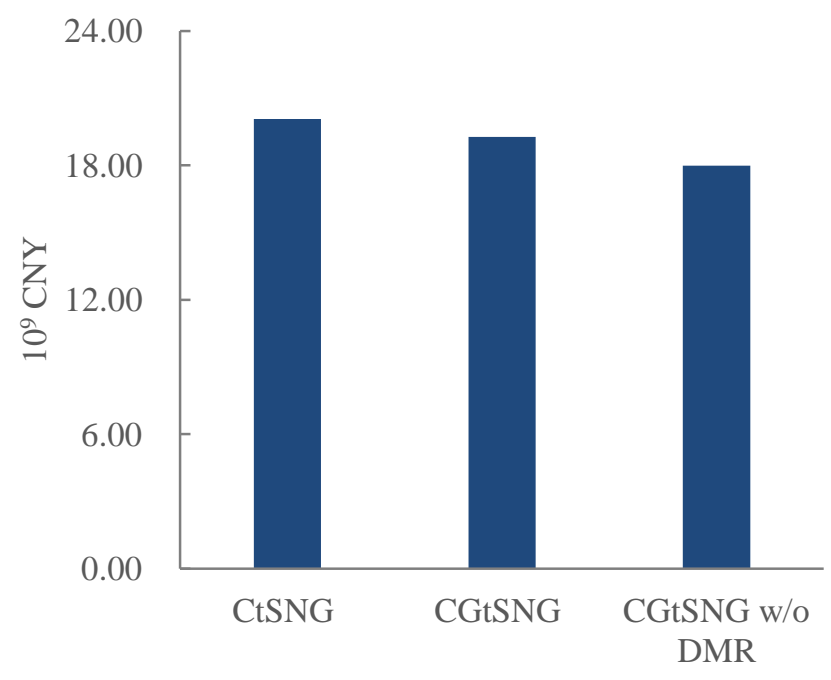

Fig. 12. Total capital investment

\section{Production cost} previous works [24]. Unit price of raw material and utilities are listed in Table 9 based on the average price in China in 2015. Since the waste COG from coking plant is not a kind of commodity, it is hard to find the price of COG. Therefore, the price of COG is estimated by comparing the heating value of COG and electricity based COG combustion power generation, as shown in Eq. (26). The price of electricity is referred to the generation price of Inner Mongolia in 2015 [25].

$390 \quad \frac{C_{\mathrm{COG}}}{C_{\text {Ele }}}=\frac{Q_{\mathrm{COG}}}{Q_{\text {Ele }}} \cdot \lambda$

391 where, $C_{\mathrm{COG}}$ is the price of COG; $Q_{\mathrm{COG}}$ is the heating value of COG; $Q_{\mathrm{Ele}}$ is the 392 heating value of electricity; $\lambda$ is the efficiency of COG combustion power 393 generation, adopted as 30\%; $C_{E l e}$ is the generation price of Inner Mongolia in 2015, adopted as $0.3 \mathrm{CNY} / \mathrm{kWh}$ 。 


\begin{tabular}{ll}
\hline Component & Economic assumptions \\
\hline (1) Raw material & Lignite $120 \mathrm{CNY} / \mathrm{t}$, Coke-oven gas $0.43 \mathrm{CNY} / \mathrm{m}^{3}$ \\
(2) Utilities & Water $2 \mathrm{CNY} / \mathrm{t}$, electricity $0.7 \mathrm{CNY} / \mathrm{kWh}$, steam $42 \mathrm{CNY} / \mathrm{GJ}$ \\
(3) Operating \& Maintenance & \\
(3.1) Operating labor & 300 labors $10000 \mathrm{CNY} /$ labor/year \\
(3.2) Direct supervisory and clerical labor & $20 \%$ of operating labor \\
(3.3) Maintenance and repairs & $2 \%$ of fixed capital investment \\
(3.4) Operating supplies & $0.7 \%$ of fixed capital investment \\
(3.5) Laboratory charge & $15 \%$ of operating labor \\
(4) Depreciation & Life period 20 years, salvage value $4 \%$ \\
(5) Plant overhead costs & $60 \%$ of $(3.1+3.2+3.3)$ \\
(6) Administrative costs & $2 \%$ of product cost \\
(7) Distribution and selling costs & $2 \%$ of product cost \\
(8) Product cost & $(1)+(2)+(3)+(4)+(5)+(6)+(7)$ \\
\hline
\end{tabular}

397 is shown in Fig. 13. As discussed before, the total capital investment of CGtSNG is

398 lower than that of CtSNG. And the feedstock of the raw material reduces a lot due to

399 the high carbon utilization efficiency. Therefore, the production cost of CGtSNG is

400 approximately $2 \mathrm{CNY} / \mathrm{m}^{3} \mathrm{SNG}$. Production cost of CGtSNG is $16.7 \%$ lower than that,

$4012.4 \mathrm{CNY} / \mathrm{m}^{3}$, of CtSNG. Production cost of CGtSNG w/o DMR is $2.28 \mathrm{CNY} / \mathrm{m}^{3} \mathrm{SNG}$,

402 which decreased 5\% due to the lower total capital investment and less raw material

403 consumption.

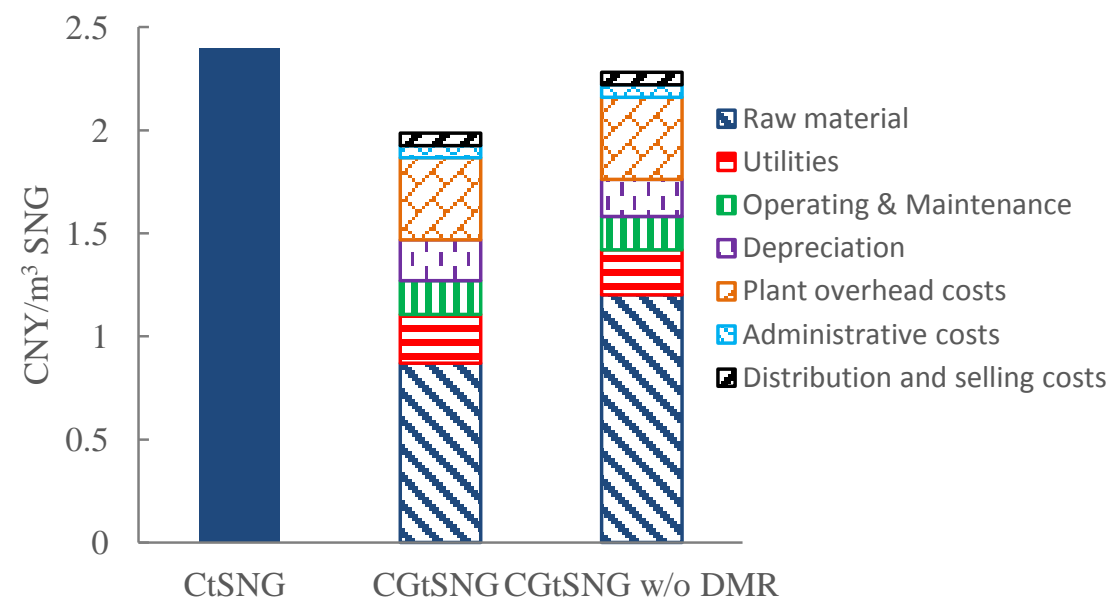

Fig. 13. Production cost 


\section{Conclusions}

This paper proposes a novel coal and COG to SNG process. In CGtSNG process, methane in COG is used for DMR reaction for reducing $\mathrm{CO}_{2}$ emission. And $\mathrm{H}_{2}$ in COG is used for adjusting the $\mathrm{H} / \mathrm{C}$ ratio of the methanation syngas. Key operational variables are analyzed. The result shows the elementary carbon efficiency reaches up to $70 \%$ and the $\mathrm{H} / \mathrm{C}$ ratio of the syngas is appropriate for the methanation when COG/coal feedstock ratio is around 0.8-0.9. A process of coal and COG to SNG without DMR unit is also proposed. Although CGtSNG w/o DMR process do not make use of $\mathrm{CO}_{2}$, the $\mathrm{CO}_{2}$ emission and energy consumption are also decreased by system integration.

The major advantages of the proposed CGtSNG process are: (1) CGtSNG enables to take advantage of the wasted COG in China's coke industry, what allows to optimize the allocation of resources and enhances the economic value of COG. (2) emission of CGtSNG and CGtSNG w/o DMR decrease by $60 \%$ and $27.8 \%$ in comparison to the CtSNG process, with the effluent discharge decrease by $72 \%$ and

424 30.9\%. (3) CGtSNG has advantaged in economic performance. Production cost of 
427

428

429

430

431

432

433

434

435

436

437

438

439

440

441

442

443

444

445

446

447

448

449

450

451

452

453

454

\section{Acknowledgements}

The authors are grateful for financial support from the China NSF projects (No.

$21136003 \&$ 21306056), and the National Basic Research Program (No. 2012CB720504).

\section{References}

[1] National Bureau of Statistics of China. China Energy Statistics Yearbook. Beijing (China): China Statistics Press; 2013. [in Chinese]

[2] Wojdyga K, Chorzelski M, Rozycka-Wronska E. Emission of pollutants in flue gases from Polish district heating sources. Journal of Cleaner Production. 2014;75:157-65.

[3] National Bureau of Statistics of China. China Energy Statistics Yearbook. Beijing (China): China Statistics Press; 2012. [in Chinese]

[4] Li C, Liu Y, Li C, Zuo Y. Analysis of the present status, the policy and application development of coal to SNG in China. Chemical Industry. 2015;33(1):1-9. [in Chinese]

[5] Li S, Jin H, Gao L, Zhang X, Ji X. Techno-economic performance and cost reduction potential for the substitute/synthetic natural gas and power cogeneration plant with $\mathrm{CO}_{2}$ capture. Energy Conversion and Management. 2014;85:875-87.

[6] Li H, Yang S, Zhang J, Qian Y. Coal-based synthetic natural gas (SNG) for municipal heating in China: analysis of haze pollutants and greenhouse gases (GHGs) emissions. Journal of Cleaner Production. 2015. dx.doi.org/10.1016/j.jclepro.2015.04.078

[7] Datang Energy and Chemical Co., Ltd. Coal to SNG project introduction of Datang Corporation in Chifeng, Inner Mongolia, 2009. [in Chinese]

[8] Greenpeace, Investigation report for coal to SNG project of Datang Corporation, 2014 [in Chinese]. www.greenpeace.org.cn/keqi-ctg-pollution-report/ (Accessed 01/10/2015)

[9] Razzaq R, Li C, Zhang S. Coke oven gas: Availability, properties, purification, and utilization in China. Fuel. 2013;113:287-99.

[10] Hao Y, Huang Y, Gong M, Li W, Feng J, Yi Q. A polygeneration from a dual-gas partial catalytic oxidation coupling with an oxygen-permeable membrane reactor. Energy Conversion and 
[11] Man Y, Yang S, Zhang J, Qian Y. Conceptual design of coke-oven gas assisted coal to olefins process for high energy efficiency and low $\mathrm{CO}_{2}$ emission. Applied Energy. 2014;133:197-205.

[12] Li S, Jin H, Gao L. Cogeneration of substitute natural gas and power from coal by moderate recycle of the chemical unconverted gas. Energy. 2013;55:658-67.

[13] Liu X, Yang S, Hu Z, Qian Y. Simulation and assessment of an integrated acid gas removal process with higher $\mathrm{CO}_{2}$ capture rate. Computers \& Chemical Engineering. 2015;85:48-57.

[14] Rahemi N, Haghighi M, Babaluo AA, Allahyari S, Jafari MF. Syngas production from reforming of greenhouse gases $\mathrm{CH}_{4} / \mathrm{CO}_{2}$ over $\mathrm{Ni}-\mathrm{Cu} / \mathrm{Al}_{2} \mathrm{O}_{3}$ nanocatalyst: Impregnated vs. plasma-treated catalyst. Energy Conversion and Management. 2014;84:50-9.

[15] Aw MS, Zorko M, Osojnik Črnivec IG, Pintar A. Progress in the synthesis of catalyst supports: synergistic effects of nanocomposites for attaining long-term stable activity in $\mathrm{CH}_{4}-\mathrm{CO}_{2}$ dry Reforming. Industrial \& Engineering Chemistry Research. 2015;54(15):3775-87.

[16] Luyben WL. Design and control of the dry methane reforming process. Industrial \& Engineering Chemistry Research. 2014;53(37):14423-39.

[17] Li S, Ji X, Zhang X, Gao L, Jin H. Coal to SNG: Technical progress, modeling and system optimization through exergy analysis. Applied Energy. 2014;136:98-109.

[18] Yadav R, Rinker RG. Steady-state methanation kinetics over a Ni/ $\mathrm{Al}_{2} \mathrm{O}_{3}$ catalyst. Canadian Journal of Chemical Engineering. 1993;71(2):202-8.

[19] Man Y, Yang S, Xiang D, Li X, Qian Y. Environmental impact and techno-economic analysis of the coal gasification process with/without $\mathrm{CO}_{2}$ capture. Journal of Cleaner Production.

[22] Keipi T, Hankalin V, Nummelin J, Raiko R. Techno-economic analysis of four concepts for 
486 [23] Yu B-Y, Chien IL. Design and Economic Evaluation of a Coal-to-Synthetic Natural Gas Process. 487 Industrial \& Engineering Chemistry Research. 2015;54(8):2339-52.

488 [24] Xiang D, Yang S, Qian Y. Techno-economic analysis and comparison of coal based olefins processes. Energy Conversion and Management. 2016;110:33-41.

490 [25] National Development and Reform Commission of China. Notification on price reduction of power generation and electricity for industrial and commercial use, 2015 [in Chinese]. www.sdpc.gov.cn/zcfb/zcfbtz/201504/t20150417_688505.html (Accessed 01/10/2015) 